\title{
Sandwich compression of sugi (Cryptomeria japonica) and hinoki (Chamaecyparis obtusa) wood: density distribution, surface hardness and their controllability
}

\author{
Rongfeng Huang ${ }^{1 *}$, Noboru Fujimoto ${ }^{2}$, Hiroki Sakagami ${ }^{2}$ and Shanghuan Feng ${ }^{3}$
}

\begin{abstract}
The sapwood and heartwood of plantation sugi wood (Cryptomeria japonica), and plantation hinoki (Chamaecyparis obtusa) wood were flat-sawn into timbers, then kiln-dried to a MC level below $12 \%$. These timbers were further processed into specific sizes and wetted on the surfaces, preheated at $150^{\circ} \mathrm{C}$ and radially compressed into sandwich compressed timbers. Density distribution, compressed layer(s) position and thickness, surface hardness were investigated. It was demonstrated that sugi and hinoki timbers were both applicable for sandwich compression. By controlling the preheating time, sugi heartwood timber, sugi sapwood timber and hinoki timber can be all sandwich compressed, which resulted in surfaces compressed timbers, interior compressed timbers and center compressed timbers. When sugi timbers were sandwich compressed, density only tremendously increased in the earlywood. The increased density of the compressed sugi earlywood was independent of compressed layer(s) position, compressing distance or annual growth width, while for hinoki timbers compression, density increased both in earlywood and latewood. Surface hardness of the uncompressed sugi sapwood was almost twice of that of the uncompressed sugi heartwood. Surface compression sharply increased the surface hardness of sugi heartwood and sugi sapwood. Interior compression and center compression also contributed to increased surface hardness for the compressed timbers, but to smaller extents. Surface hardness change due to the surface compression was consistent with the surface average density change of timbers. Compression layer(s) position exerted statistically significant effects on the surface hardness, while surface hardness of the compressed wood was almost unrelated to the original density of the used wood or average density of the sandwich compressed wood. However, bigger compressing distance led to bigger surface hardness for the surface compressed wood.
\end{abstract}

Keywords: Sandwich compression, Sugi heartwood, Sugi sapwood, Hinoki wood, Density distribution, Surface hardness

\section{Introduction}

Wood compression is an efficient way to enhance wood hardness and improve wood strength, and thus diversify wood applications. Traditional wood compression

\footnotetext{
${ }^{*}$ Correspondence: huangrf@caf.ac.cn

${ }^{1}$ Key Lab of Wood Science and Technology of State Forestry

and Grassland Administration, Research Institute of Wood Industry,

Chinese Academy of Forestry, Beijing 100091, People's Republic of China

Full list of author information is available at the end of the article
}

achieved via hygro-thermal softening has been widely studied and extensive researches have been reported on wood softening, wood plastic deformation, wood properties change after compression, wood compression fixation and the relevant mechanisms [1-10]. Compressed wood applications for furniture, floor and construction material have been scaled up to industrial level [11, 12]. Traditional wood compression for high density and improved hardness requires big compression rate, which 
sacrifices relatively big wood volumes and thus increases the production cost. One alternative way for the traditional wood compression is wood surface compression, coupled with chemical treatment with polymers such as phenol formaldehyde resin, melamine formaldehyde resin or polymeric methyl diphenyl diisocyanate (pMDI) resin, etc., which improves wood surface properties and dimension stability $[3,13-16]$. However, toxic chemicals are released from the compressed wood during the services due to the use of polymers containing free formaldehyde in the compression [13-15].

Sandwich compression technology applying hygrothermal pre-treatment can effectively improve wood properties [17] with a minimal sacrifice of wood volume. Different from traditional wood compression, compression in the sandwich compressed wood can be controlled to occur in some specific area/zone where it is required inside wood, while other zone in the same wood timber is uncompressed or even intact. Since the compressed layer(s) and thickness are both adjustable, this technology can minimize wood volume loss caused by the compression. So far, sandwich compression has demonstrated great successes for poplar wood [18-23], which is a typical plantation diffuse-porous hardwood. By adjusting the preheating temperature and time, compressed layer(s) position and thickness are both controllable.

Sugi (Cryptomeria japonica) and hinoki (Chamaecyparis obtuse) as the most commonly planted coniferous species in Japan have been widely applied as building materials in houses in Japan and have been extensively used as ceiling board, wall paneling, and posts as well [24]. Similar to other plantation wood species, the comparatively low density of sugi and hinoki wood to some degree limits their applications. Properties of sugi heartwood and sapwood vary to a great extent. In this study, plantation sugi heartwood, sugi sapwood and hinoki wood are used as the raw material, to investigate the effect of heartwood, sapwood, wood species, compressing distance and preheating time on sandwich compression formation, density distribution and surface hardness.

\section{Materials and methods}

\section{Materials}

Plantation sugi (Cryptomeria japonica) and hinoki (Chamaecyparis obtusa) wood harvested in Kyushu, Japan were used as the raw materials in this study. Both sugi and hinoki wood were flat-sawn into timbers and kiln-dried to a moisture content (MC) level below $12 \%$. Sugi timbers were then processed and separated into heartwood timbers and sapwood timbers. For sugi heartwood timbers, they were further processed into specimens with a dimension of $250 \mathrm{~mm}(\mathrm{~L}) \times 120 \mathrm{~mm}(\mathrm{~T}) \times 30$ $\mathrm{mm}(\mathrm{R})$, and specimens with a size of $250 \mathrm{~mm}(\mathrm{~L}) \times 120$
$\mathrm{mm}(\mathrm{T}) \times 26 \mathrm{~mm}(\mathrm{R})$. While for sugi sapwood timbers, they were processed into specimens with a size of 250 $\mathrm{mm}(\mathrm{L}) \times 120 \mathrm{~mm}(\mathrm{~T}) \times 30 \mathrm{~mm}(\mathrm{R})$. Hinoki timbers were processed into a dimension of $250 \mathrm{~mm}(\mathrm{~L}) \times 120 \mathrm{~mm}$ $(\mathrm{T}) \times 25 \mathrm{~mm}(\mathrm{R})$.

\section{Sandwich compression}

Before sandwich compression, wood specimens were soaked in water for $0.5-3.0 \mathrm{~h}$, to increase wood surface water loading rate by an average level of $0.05 \mathrm{~g} / \mathrm{cm}^{2}$. Before soaking in water, end sealing with wax is not essentially necessary according to our research. The specimens were then preheated at $150{ }^{\circ} \mathrm{C}$ and compressed from the original thickness to the target thickness. After the specimens were compressed to the target thickness with the distance-bars, heating was ceased and the pressure was adjusted to $1.0 \mathrm{MPa}$. After $2.0 \mathrm{~h}$, the compressed timbers were removed from the platens. For the preheating process, $15 \mathrm{~s}, 180 \mathrm{~s}$ or $1500 \mathrm{~s}$ of preheating time was applied, to form three types of sandwich compressed timbers, namely surfaces compressed wood, interior compressed wood and center compressed wood. Sandwich compression under each condition was replicated for 6 times. The schematic diagram for sample preparation and sandwich compression is as shown in Fig. 1. The original and target thickness of the sandwich compressed specimens are as listed in Table 1.

\section{Tests of density distribution and surface hardness}

For the density test, specimens with a length of $5.0 \mathrm{~mm}$ (L) along the longitudinal direction of the compressed timbers were cut in the compressed timber center. These specimens were then conditioned at $20{ }^{\circ} \mathrm{C}, 65 \% \mathrm{RH}$ with the control sample to constant weight. Density was tested along the thickness of these specimens by soft X-ray (Softex K-4) combined with image processing. As for the surface hardness tests, specimens with a length of $50 \mathrm{~mm}$ along the longitudinal direction was cut from the compressed lumber and the control specimens. After the specimens were conditioned at $20{ }^{\circ} \mathrm{C}, 65 \% \mathrm{RH}$, Brinell hardness was tested in according with JIS Z 2101-1994 [25] hardness test.

Definition of compressed layer(s): in the sandwich compressed specimens, areas or zones with an average density that was $10 \%$ higher than the associated average control wood density is defined as the compressed layer(s) [17].

\section{Results and discussion}

Controllability of compressed layer(s) position and thickness

Figure 2 shows the regular photos and soft X-ray images of sandwich compressed sugi and hinoki timbers on the 


\section{a: Flat-sawn lumber}

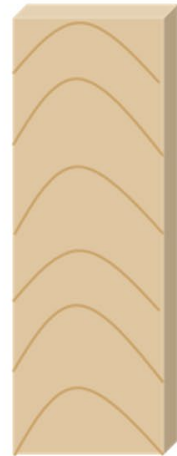

\section{b: Soaking \& setting}

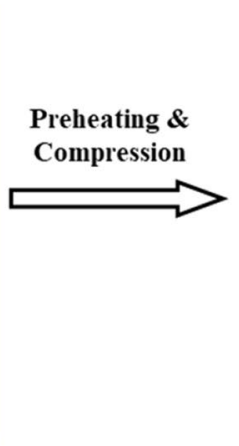

\section{c : Structure models of} sandwich compressed wood

\section{d: Photos of sandwich compressed wood}

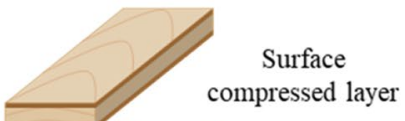

Interior compressed layer

Center compressed layer

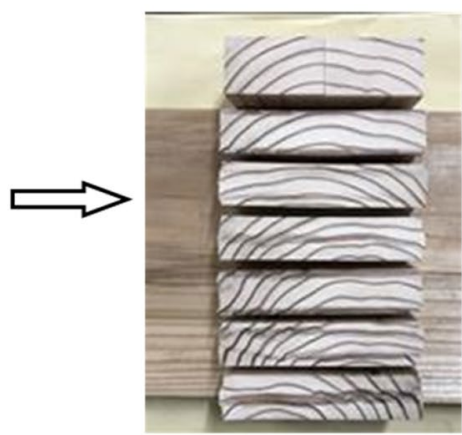

Fig. 1 Schematic diagram for sample preparation and sandwich compression

Table 1 Original and target thickness of timbers specimens

\begin{tabular}{lllc}
\hline & $\begin{array}{l}\text { Original } \\
\text { thickness } \\
(\mathbf{m m})\end{array}$ & $\begin{array}{l}\text { Target } \\
\text { thickness } \\
(\mathbf{m m})\end{array}$ & $\begin{array}{l}\text { Compressing } \\
\text { distance }(\mathbf{m m})\end{array}$ \\
\hline Sugi heartwood & 26 & 20 & 6 \\
Sugi sapwood & 30 & 20 & 10 \\
Hinoki wood & 30 & 24 & 6 \\
\hline
\end{tabular}

transverse section. The comparatively dark area is the compressed layer(s) in the regular photos; while in the soft X-ray images, the lighter area is the compressed layer(s) in the sandwich compressed timbers. When the compressing distance is $5 \mathrm{~mm}, 6 \mathrm{~mm}$ or $10 \mathrm{~mm}$, various sandwich compressed timbers with different distance between wood surface to the associated compressed layer can be made by changing the preheating time. Bigger compressing distance results in bigger compressed layer(s) thickness, while the position of the compressed
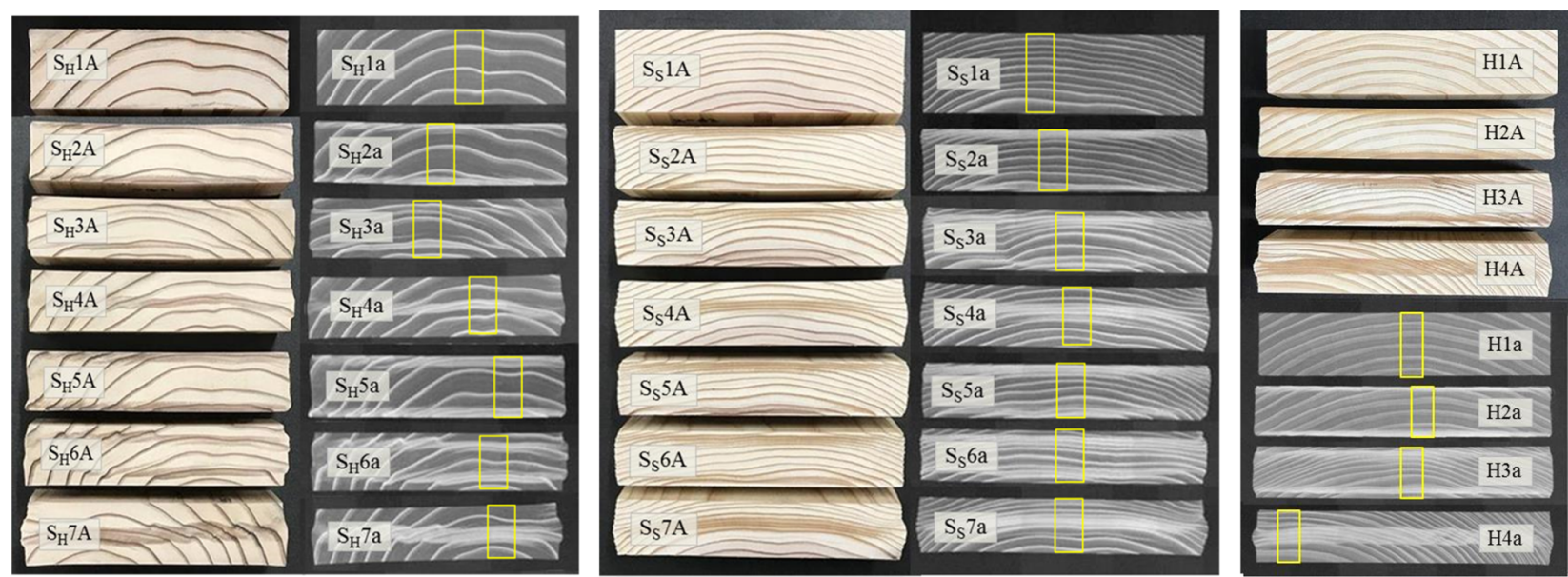

Fig. 2 Photos and soft $X$-ray images of the transverse section of sugi heartwood, sugi sapwood and hinoki wood. $S_{H}, S_{S}, H$ in the labels represent sugi heartwood, sugi sapwood and hinoki wood. Labels containing ' 1 ' represent the control specimens. Labels containing ' 2 ', ' ' 3 ', and ' 4 ', respectively, represent the sandwich timbers with surfaces compressed (preheating time: $15 \mathrm{~s}$ ), interior compressed (preheating time: $180 \mathrm{~s}$ ) and center compressed (preheating time: $1500 \mathrm{~s}$ ) when the compression is $6 \mathrm{~mm}$ or $5 \mathrm{~mm} ;{ }^{\prime} 5^{\prime}, 6^{\prime},{ }^{\prime} 7^{\prime}$ in the labels represent the sandwich wood with surface compressed, interior compressed and center compressed when the compressing distance is $10 \mathrm{~mm}$; labels containing 'A' represent photos; labels containing 'a' represent $X$-ray images; sections in the yellow rectangle are the area where the density was tested 
layer(s) is independent of wood species or compressing distance. As a result of preheating time extension, compressed layers move into timbers interior. When the preheating time is $15 \mathrm{~s}$, compressed layers are formed on timbers surfaces; while compressed layers are formed in timbers interior ( $1 \mathrm{~mm}$ interior to the surface) when the preheating time is $180 \mathrm{~s}$. When the preheating time is further extended to $1500 \mathrm{~s}$, only one compressed layer is formed in wood center. This demonstrates that sugi heartwood, sugi sapwood and hinoki wood are all applicable for sandwich compression. During the process, preheating time is a key variable for controlling the compressed layer(s) position in wood. Our previous studies have proved that by controlling the preheating time for poplar wood compression, compressed layer(s) position can be controlled to wood surfaces, wood interior or wood center [21]. Compressed layers(s) thickness can be also controlled via changing the compressing distance and water soaking time [18]. As for sugi and hinoki wood, especially for the sugi wood with distinct density variation between earlywood and latewood, the compressed layer(s) can be also controlled to wood surface, wood interior or wood center by controlling the variables as reported for poplar wood sandwich compression.

Moisture/water and temperature are the most important variables on which wood softening and yield stress are dependent [21]. For woods with the same moisture content, preheating contributes to a higher temperature elevation rate on the surface than that in wood interior, forming a big temperature gradient along wood thickness (compressing direction). And higher preheating temperature results in bigger temperature gradients [26-28]. Also, preheating temperature affects moisture diffusion co-efficiency and thus changes the moisture distribution along wood thickness [29, 30]. Accordingly, for wood preheated for different preheating time, different temperature gradient and moisture content gradient are both formed on the thickness direction, leading to yield stress gradient on the direction of thickness. Since some regions are of high moisture content and high temperature in wood, the corresponding yield stress is much smaller and these regions can be compressed much easier [31]. Thus, preheating for various preheating time contributes to three types of compressed layers, namely surface compressed layer, interior compressed layer and center compressed layer.

In addition, wood structure including ray, grain direction and density all affect wood sandwich compression. These structures can affect wood sandwich compression during soaking in water, heat transfer, drying and compression. In our research, we found that wood grain direction especially Japanese hinoki heartwood grain exerts great effects on the position of the compressed layers inside wood. When hinoki heartwood is center compressed, the compressed layer position shift on the radial and tangential directions. This kind of shift is relevant to wood grain direction. We will investigate these more in future.

\section{Density distribution along the thickness of the sandwich compressed wood}

Specimens for density tests are sampled from the areas as shown in the yellow rectangles in Fig. 2 and the density distribution in the compressed timbers are as illustrated by Figs. 3, 4 and 5. For the uncompressed sugi wood, annual growth ring width in heartwood is bigger than that in sapwood, and density variation as big as $0.500 \mathrm{~g} / \mathrm{cm}^{3}$ exists between earlywood and latewood in both heartwood and sapwood. After sandwich compression, latewood is almost uncompressed, while the density of earlywood increases sharply from $0.200 \mathrm{~g} /$ $\mathrm{cm}^{3}$ to $\sim 0.700 \mathrm{~g} / \mathrm{cm}^{3}$. The increased density of the compressed earlywood is independent of compressed layer(s) position, compressing distance or annual growth width. The average density of the uncompressed hinoki wood is $0.481 \mathrm{~g} / \mathrm{cm}^{3}$, and the density variation between the earlywood and latewood is only $0.200 \mathrm{~g} / \mathrm{cm}^{3}$. After sandwich compression, both earlywood and latewood in hinoki are compressed. The maximum density of the compressed layer(s) reaches to $0.907 \mathrm{~g} / \mathrm{cm}^{3}$, higher than the latewood density.

It is also observed that for both sugi and hinoki timbers, the compressed layer(s) density is remarkably higher while the density distribution in uncompressed areas in the sandwich compressed wood is almost the same as that of the controls. This suggests that by controlling water uptake on wood surfaces and preheating time, the compression can be well controlled to some specific wood areas or zone while retaining the rest areas of wood uncompressed and intact in terms of density.

Table 2 shows the characteristic density values of sugi heartwood, sugi sapwood and hinoki wood. The maximum density of compressed layer(s) in compressed sugi heartwood and compressed hinoki wood are both over $0.800 \mathrm{~g} / \mathrm{cm}^{3}$. For surfaces compressed timbers, the average density of the compressed layers ranges in $0.661-0.816 \mathrm{~g} / \mathrm{cm}^{3}$, which reach to the density of the traditionally whole compressed sugi heartwood with $50 \%$ 

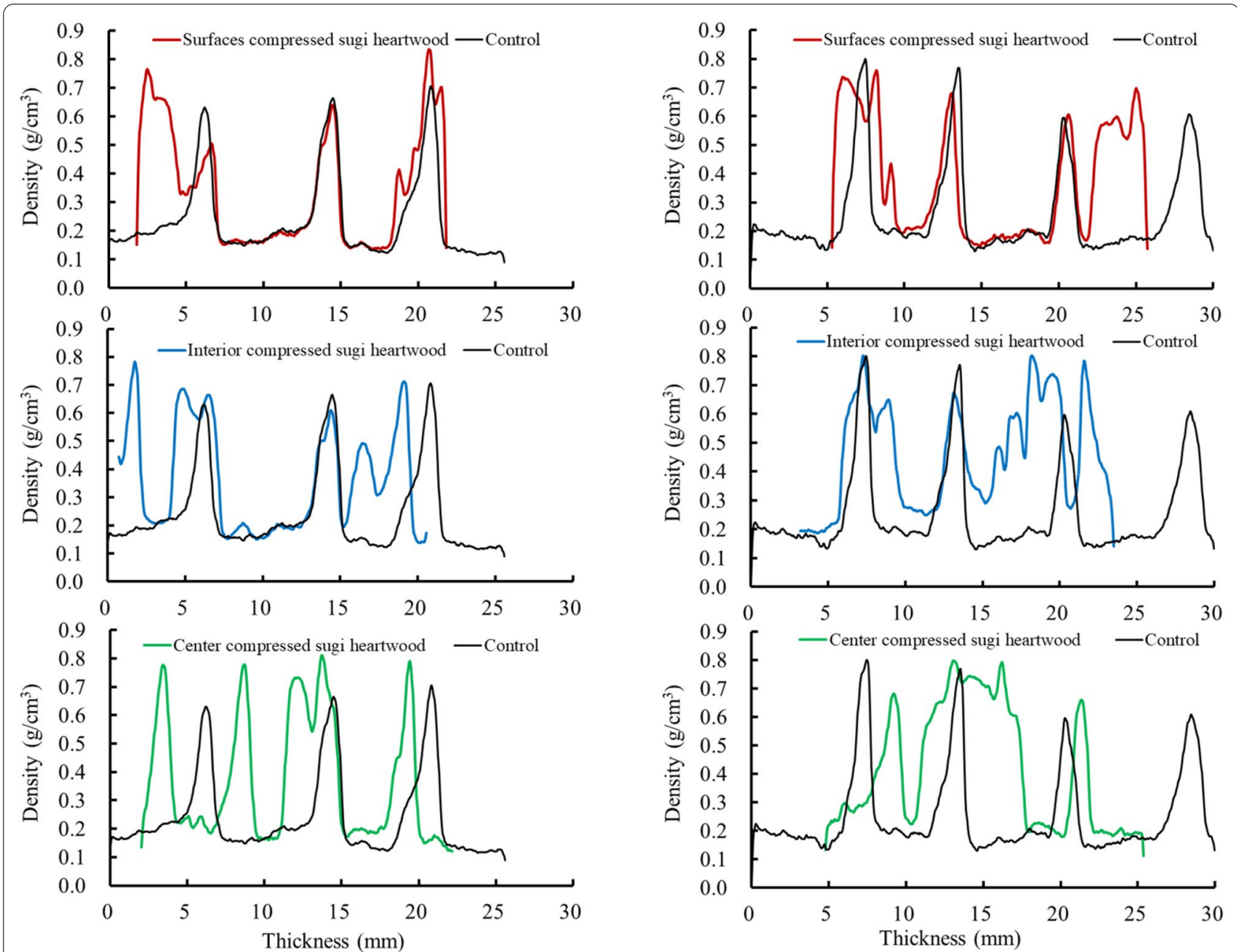

Fig. 3 Density distribution along the thickness of sandwich compressed sugi heartwood timber (left: compressed from 26 to $20 \mathrm{~mm}$; right: compressed from 30 to $20 \mathrm{~mm}$ )

compressing rate [32]. Even though density of sugi sapwood is bigger than that of sugi heartwood, the maximum and average density of the compressed layer(s) in sugi sapwood is smaller than that of the sugi heartwood, when the compressing distance is $6 \mathrm{~mm}$. While when the compressing distance is $10 \mathrm{~mm}$, the maximum and average density of the compressed layer(s) in sugi sapwood is reversely bigger than that of the sugi heartwood. The formed compressed layer(s) thickness in sugi sapwood is bigger than that formed in the sugi heartwood, which means the compressed area in sugi sapwood is bigger than that in sugi heartwood, regardless of the compressing distance. This can be due to the stronger water absorption of sugi sapwood than heartwood and the water permeates faster in sapwood than in heartwood, resulting in a bigger softened area during the preheating process [33]. For hinoki wood, compressing distance does affect the average density of the compressed layer(s). The maximum and average density of compressed layer(s) in hinoki wood are both higher than that in sugi wood. This can be related to the annual growth rings structure and permeability properties of these two wood species.

\section{Hardness of the sandwich compressed timbers}

Table 3 includes the surface hardness of sugi heartwood, sugi sapwood, and hinoki wood, and their changes 

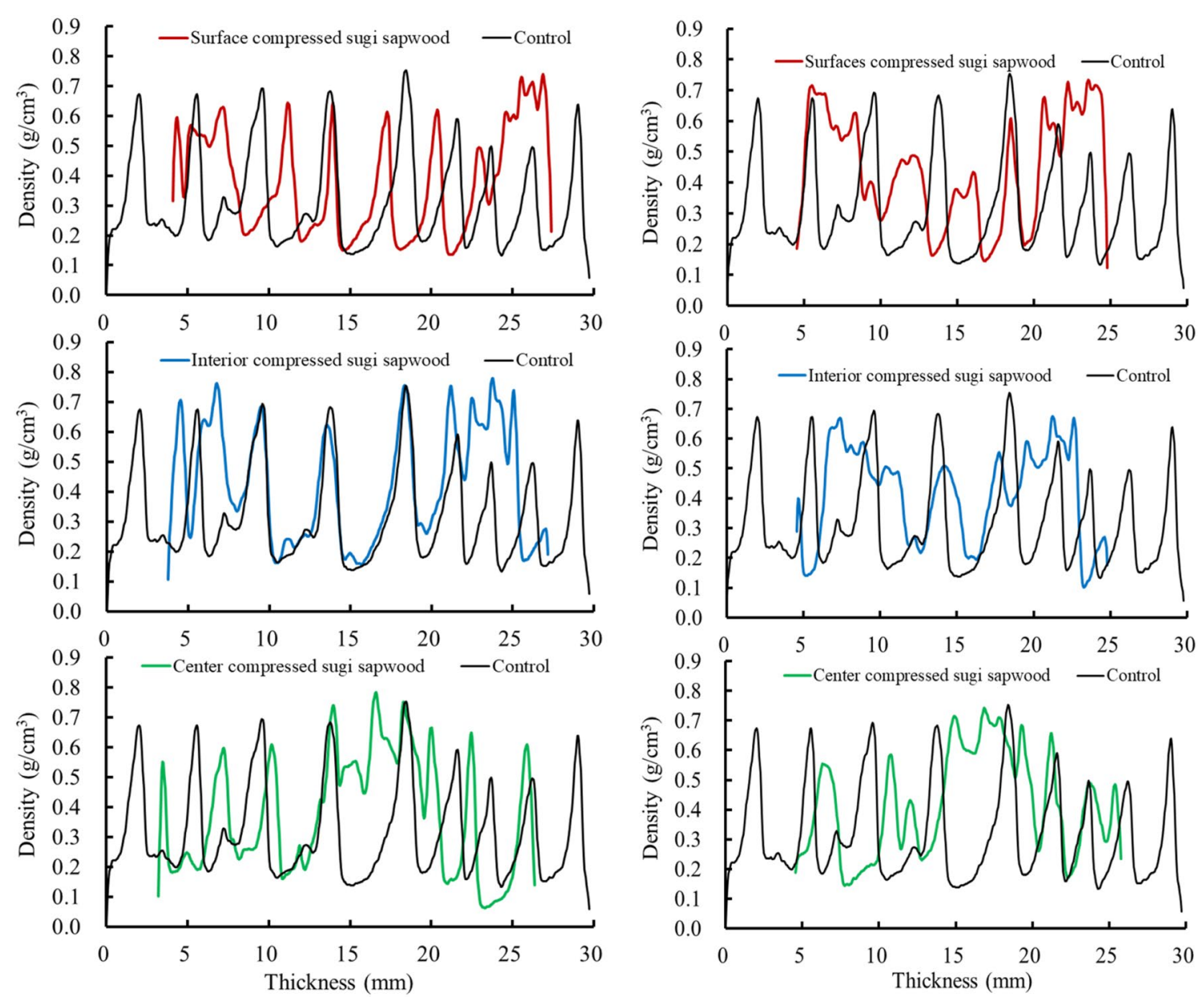

Fig. 4 Density distribution along the thickness of sandwich compressed sugi sapwood timber (left: compressed from 30 to 24 mm; right: compressed from 30 to $20 \mathrm{~mm}$ )

resulting from the sandwich compression. Hardness of the uncompressed sugi sapwood is almost twice of that of the sugi heartwood, the surface hardness of the uncompressed sugi heartwood is $4.34 \mathrm{~N} / \mathrm{mm}^{2}$ while for the uncompressed sugi sapwood, it is $8.24 \mathrm{~N} / \mathrm{mm}^{2}$. After compression, surface hardness of the surface compressed sugi heartwood and sugi sapwood increase by $64.55-240.75 \%$, to over $27.92 \mathrm{~N} / \mathrm{mm}^{2}$. For the interior compressed timbers, the surface hardness is all over 8.50 $\mathrm{N} / \mathrm{mm}^{2}$, while for the center compressed timbers, the surface hardness mostly ranges in $6.40-8.61 \mathrm{~N} / \mathrm{mm}^{2}$. Surface hardness change due to the surface compression is consistent with the surface average density change.
Compression layer(s) position exerts remarkable effects on the surface hardness, and the surface hardness of the compressed wood is almost unrelated to the original density of the used wood or average density of the sandwich compressed wood. However, bigger compressing distance leads to bigger surface hardness for the surface compressed timbers.

Surface hardness of hinoki wood is $11.75 \mathrm{~N} / \mathrm{mm}^{2}$, much bigger than that of sugi heartwood or sapwood. When the surface is compressed by $5 \mathrm{~mm}$, the surface hardness increases by $100.27 \%$, to $23.04 \mathrm{~N} / \mathrm{mm}^{2}$. While for the interior and center compression, the surface hardness does not increase remarkably. This suggests that 


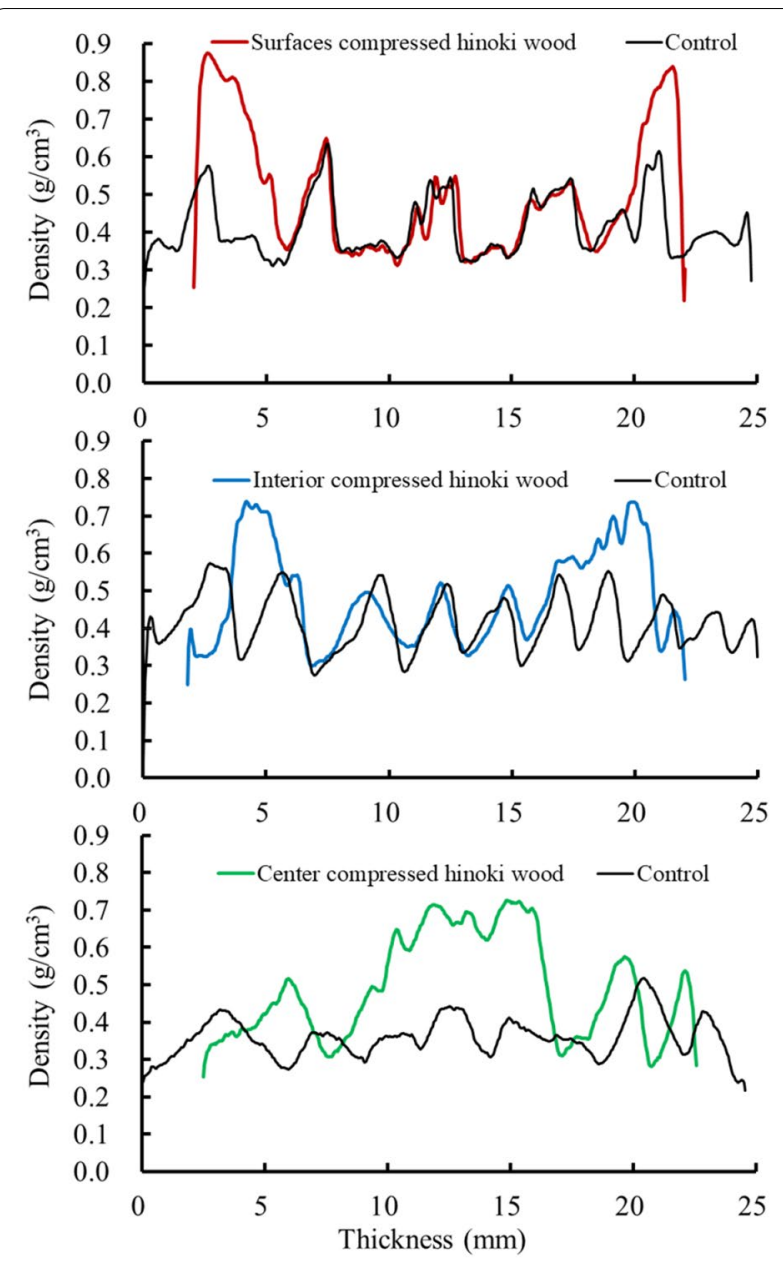

Fig. 5 Density distribution along the thickness of sandwich compressed hinoki timber (compressed from 25 to $20 \mathrm{~mm}$ )

hinoki wood surface compression leads to better results, and interior and center compression contribute to much less compression on the surface than surface compression itself.

Surface hardness of surface compressed wood, interior compressed wood and center compressed wood was $\mathrm{F}$ tested. The results indicate that, for sugi sapwood with the compressing distance of $6 \mathrm{~mm}$, the surface hardness variation among the surface compressed wood, interior compressed wood and center compressed wood is statistically significant $(<0.05)$. While for the sandwich compressed wood produced under any other circumstances, the surface hardness of the surface compressed wood, interior compressed wood and center compressed is statistically highly significantly different $(<0.01)$.
Surface hardness of compressed wood is generally significantly related with wood density $[17,34]$. Since sandwich compression can selectively densify wood surface or interior where required while the other areas/ zones in wood are almost intact [17-23], much less wood compressing percent is required to improve the surface hardness than traditional wood compression. In wood sandwich compression, density of wood interior beside the surface can be significantly increased based on the requirement, which can accordingly increase the surface hardness of the compressed wood. This can save wood volume as well as reduce the compressed wood manufacture cost. In this study, when sugi and hinoki timbers are surface compressed with a compression rate of $20 \%$, density of wood interior area that is $3 \mathrm{~mm}$ below wood surfaces reaches to over $0.641 \mathrm{~g} / \mathrm{cm}^{3}$ and the surface hardness correspondingly increases to over $9.6 \mathrm{~N} /$ $\mathrm{mm}^{2}$. This improvement is independent of the original hardness of sugi wood or hinoki wood. All these demonstrated that compression of sugi wood and hinoki wood can be controlled to position the compressed layer(s), thus control the surface hardness of the compressed wood. By sandwich compression, applications of sugi wood and hinoki wood can be extended to wood products such as wood floor and furniture.

\section{Conclusions}

This study demonstrates that both sugi wood and hinoki wood are applicable for sandwich compression. By controlling the preheating time, both sugi wood and hinoki wood can be compressed into surface compressed wood, interior compressed and center compressed wood. Compressed area inside wood depends on wood species. Sandwich compression of sugi wood only takes place in earlywood, and the increased density of the compressed sugi earlywood is independent of compressed layer(s) position, compression or annual growth width. For hinoki wood sandwich compression, compression occurs in both earlywood and latewood. Hardness of the uncompressed sugi sapwood is almost twice of that of the sugi heartwood. Surface hardness of sugi heartwood and sugi sapwood both sharply increase after surface compression. Interior compression and center compression increase the surface hardness as well, but to smaller extents. Surface hardness change due to the surface compression is consistent with surface average density change. Compressed layer(s) position exerts statistically significant effects on the surface hardness, whereas the surface hardness of the compressed wood is almost unrelated to the original density of the 


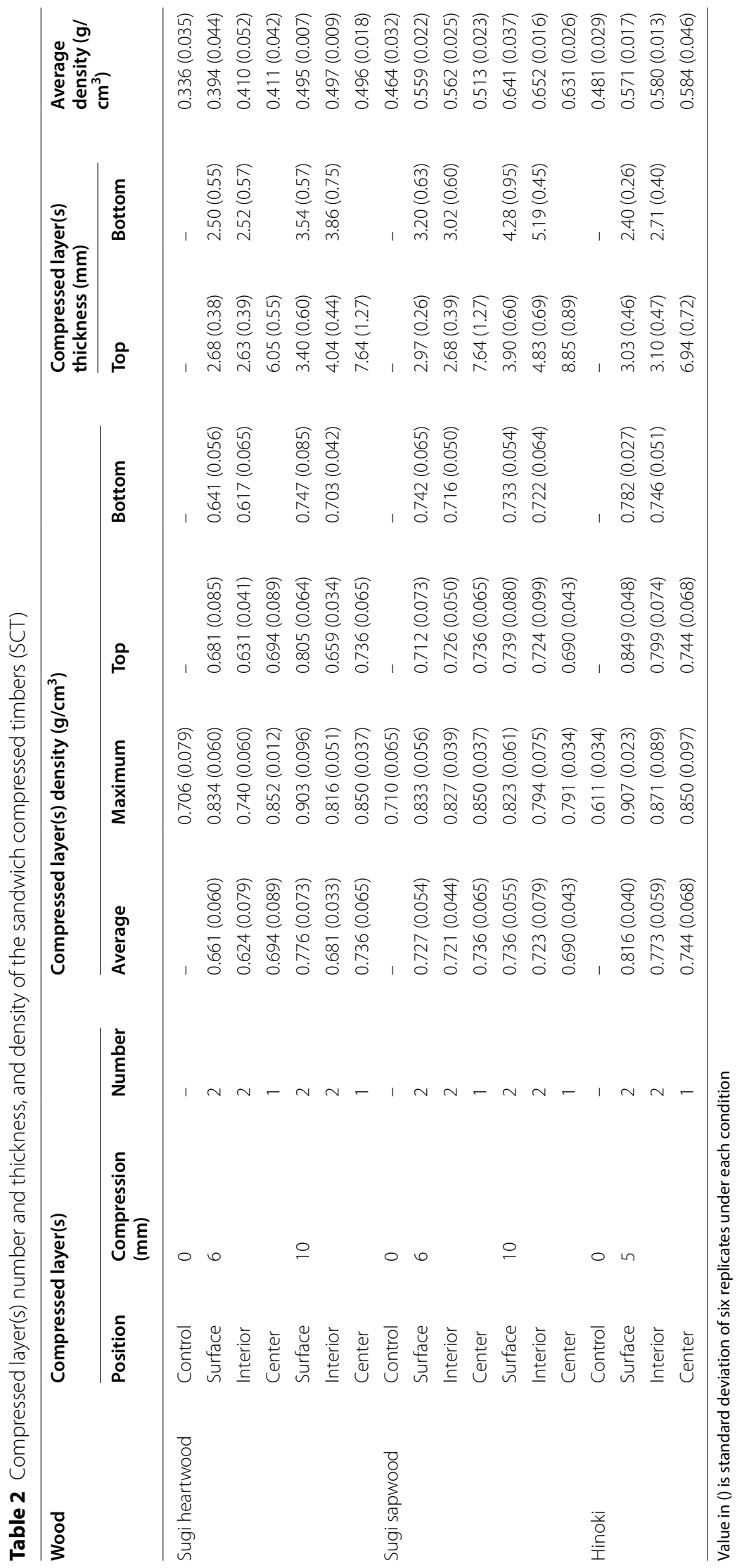


Table 3 Compressed layer(s) position, compression percent, surface hardness

\begin{tabular}{|c|c|c|c|c|c|}
\hline Wood & $\begin{array}{l}\text { Position of compressed } \\
\text { layer(s) }\end{array}$ & Compression (mm) & $\begin{array}{l}\text { Compression rate } \\
\text { (\%) }\end{array}$ & $\begin{array}{l}\text { Surface hardness (N/ } \\
\mathrm{mm}^{2} \text { ) }\end{array}$ & $\begin{array}{l}\text { Surface hardness } \\
\text { increasing } \\
\text { percentage (\%) }\end{array}$ \\
\hline \multirow[t]{7}{*}{ Sugi heartwood } & Control & 0 & - & $4.34(0.71)$ & - \\
\hline & Surface & 6 & 23.1 & $10.49(0.61)$ & 141.53 \\
\hline & Interior & & & $8.60(1.18)$ & 98.84 \\
\hline & Center & & & $6.40(0.99)$ & 47.65 \\
\hline & Surface & 10 & 33.3 & $12.15(1.34)$ & 181.37 \\
\hline & Interior & & & $8.85(1.27)$ & 104.60 \\
\hline & Center & & & $7.02(1.26)$ & 62.08 \\
\hline \multirow[t]{7}{*}{ Sugi sapwood } & Control & 0 & & 8.24 (1.19) & - \\
\hline & Surface & 6 & 20.0 & $13.51(1.61)$ & 64.55 \\
\hline & Interior & & & $9.60(1.03)$ & 16.64 \\
\hline & Center & & & $8.83(0.84)$ & 7.25 \\
\hline & Surface & 10 & 33.3 & $27.92(2.67)$ & 240.75 \\
\hline & Interior & & & $13.19(1.97)$ & 60.60 \\
\hline & Center & & & $8.61(0.81)$ & 4.55 \\
\hline \multirow[t]{4}{*}{ Hinoki } & Control & 0 & & $11.75(1.85)$ & - \\
\hline & Surface & 5 & 20.0 & $23.04(2.70)$ & 100.27 \\
\hline & Interior & & & $14.39(2.29)$ & 23.52 \\
\hline & Center & & & $12.17(1.06)$ & 3.91 \\
\hline
\end{tabular}

Value in () is standard deviation of six replicates under each condition

used wood or average density of the sandwich compressed wood. However, compressed wood with high compression percent display high surface hardness.

\section{Abbreviation}

SCT: Sandwich compressed timber

\section{Acknowledgements}

The authors acknowledge financial support by the Nature Science Foundation of China (Grant No. 31670557), and the National Nonprofit Institute Research Grant of CAF (No. CAFYBB2018ZC003).

\section{Authors' contributions}

$\mathrm{RH}$ designed and carried out the experiments and is the major contributor in writing the manuscript; NF and HS prepared the wood samples, and tested the surface hardness, and summarized the results; SF discussed the results with $\mathrm{RH}$, and committed to polish the language in the manuscript. All authors read and approved the final manuscript.

\section{Funding}

Nature Science Foundation of China (Grant No. 31670557), and the National Nonprofit Institute Research Grant of CAF (No. CAFYBB2018ZC003).

\section{Availability of data and materials}

Not applicable.

\section{Declarations}

\section{Competing interests}

The authors declare that they have no competing interests.

\section{Author details}

${ }^{1}$ Key Lab of Wood Science and Technology of State Forestry and Grassland Administration, Research Institute of Wood Industry, Chinese Academy of Forestry, Beijing 100091, People's Republic of China. ${ }^{2}$ Laboratory of Wood Material Technology, Faculty of Agriculture, Kyushu University, Fukuoka 8190395, Japan. ${ }^{3}$ Research \& Development Discovery Center, Zeroignition Technologies Inc, Coquitlam, BC V3K 5Z6, Canada.

Received: 4 November 2020 Accepted: 26 April 2021

Published online: 02 June 2021

\section{References}

1. Norimoto M (1993) Large compressive deformation in wood. Mokuzai Gakkaishi 39(8):867-874

2. Liu YX, Norimoto M, Morooka T (1993) The large compressive deformation of wood in the transverse direction. I. Relationships between stress-strain diagram and specific gravities of wood. Mokuzai Gakkaishi 39(10):1140-1145

3. Inoue M, Norimoto M, Tanahashi M, Rowell RM (1993) Steam or heat fixation of compressed wood. Wood Fiber Sci 25(3):224-235

4. Inoue M, Kodama J, Yamamoto Y, Norimoto M (1998) Dimensional stabilization of compressed wood using high-frequency heating. Mokuzai Gakkaishi 44(6):410-416

5. Inoue M, Hamaguchi T, Morooka T, Higashihara T, Norimoto M, Tsunoda $T$ (2000) Fixation of compressive deformation of wood by wet heating under atmospheric pressure. Mokuzai Gakkaishi 46(4):298-304

6. Inoue M, Morooka T, Rowell RM, Norimato M, Englund F (2008) Mechanism of partial fixation of compressed wood based on a matrix nonsoftening methods. Wood Mater Sci Eng 3(3-4):126-130

7. Udaka E, Furuno T (1998) Heat compression of Sugi (Cryptomeria japonica). Mokuzai Gakkaishi 44(3):218-222 
8. Udaka E, Furuno T, Inoue M (2000) Relationship between the set recovery of compressive deformation and the moisture in wood specimens using a closed heating system. Mokuzai Gakkaishi 46(2):144-148

9. Udaka E, Furuno T (2003) Change of crystalline structure of compressed wood by treatment with a closed heating system. Mokuzai Gakkaishi 49(1):1-6

10. Matsumoto A, Oda H, Arima T, Fujimoto N (2012) Effect of hot- pressing on surface drying-set in Sugi columns with pith. Mokuzai Gakkaishi 58(1):23-33

11. Adachi K, Inoue M (2006) The technique of wood grain compression. Wood Ind 61(11):510-512

12. Li J, Wu YZ, Ma Y (2011) Functional wood. Science Press, Beijing

13. Inoue $M$, Norimoto $M$, Otsuka $Y$, Yamada T (1991) Surface compression of coniferous wood lumber. III Permanent set of the surface compressed layer by a water solution of low molecular weight phenolic resin. Mokuzai Gakkaishi 37(3):234-240

14. Inoue M, Ogata S, Kawai S, Rowell RM (1993) Fixation of compressed wood using Melamine-Formaldehyde resin. Wood Fiber Sci 25(4):404-410

15. Gabrielli CP, Kamke FA (2010) Phenol-formaldehyde impregnation of densified wood for improved dimensional stability. Wood Sci Technol 44(1):95-104

16. Adachi K, Inoue M, Kawai S (2005) Deformation behavior of wood by roller pressing. Mokuzai Gakkaishi 51(4):234-242

17. Huang RF, Wang YW, Zhao YK, Lu JX, Zhang YM (2012) Sandwich compression of wood by hygro-thermal control. Mokuzai Gakkaishi 58(2):84-89

18. Gao ZQ, Huang RF, Lu JX, Chen ZJ, Guo F, Zhan TY (2016) Sandwich compression of wood: control of creating density gradient on lumber thickness and properties of compressed wood. Wood Sci Technol 50(4):833-844

19. Gao ZQ, Huang RF, Chang JM, Li R (2019) Sandwich compression of wood: effects of preheating time and moisture distribution on the formation of compressed layer(s). Euro J of Wood Wood Prod $77(2): 219-227$

20. Gao ZQ, Huang RF, Chang JM, Li R, Wu YM (2019) Effects of pressurized superheated-steam heat treatment on set recovery and mechanical properties of surface-compressed wood. BioResources 14(1):1718-1430

21. Li R, Gao ZQ, Feng SH, Chang JM, Wu YM, Huang RF (2018) Effects of preheating temperatures on the formation of sandwich compression and density distribution in the compressed wood. J Wood Sci 64(6):751-757
22. Li R, Huang RF, Chang JM (2019) Effect of hot pressing temperature on the density profile of compressed solid wood. BioResources 14(1):1482-1493

23. Wu YM, Qin L, Huang RF, Gao ZQ, Li R (2019) Effects of preheating temperature, preheating time and their interaction on the sandwich structure formation and density profile of sandwich compressed wood. J Wood Sci 65(1):11

24. Hon DNS, Minemura N (1991) Color and discoloration. In: Hon DNS, Shiraish N (eds) Wood and cellulosic chemistry. Marcell Dekker, New York, pp 395-454

25. JIS Z 2101 (1994) Methods of test for woods. Japanese Standards Association

26. Beard JN, Rosen HN, Adesanya BA (1983) Temperature distribution and heat transfer during the drying of lumber. Dry Technol 1(117-140):17

27. Beard JN, Rosen HN, Adesanya BA (1985) Temperature distribution in lumber during impingement drying. Wood Sci Technol 19(277-286):18

28. Tang YF, Pearson RG, Hart CA, Simpson WT (1994) A numerical model for heat transfer and moisture evaporation processes in hot-press dryingan integral approach. Wood Fiber Sci 26(78-90):19

29. Hrčka R, Babiak M, Németh $R$ (2008) High temperature effect on diffusion coefficient. Wood Res Slovak 53:37-46

30. Fotsing JAM, Tchagang CW (2005) Experimental determination of the diffusion coefficients of wood in isothermal conditions. Heat Mass Transfer 41:977-980

31. Inoue M, Norimoto M, Otsuka Y, Yamada T (1990) Surface compression of coniferous wood lumber I. A new technique to compress the surface layer. Mokuzai Gakkaishi 36:969-975

32. Kitamori A, Jung K, Mori T, Komatsu K (2010) Mechanical properties of compressed wood in accordance with the compression ratio. Mokuzai Gakkaishi 56(2):67-78

33. Takahashi T, Nakayama Y (1995) Wood science series 3-Physics. KaiseishaPress, Otsu

34. Rautkari L, Honkanen J, Hill ASC, Ridley-Ellis D, Hughes M (2014) Mechanical and physical properties of thermally modified Scots pine wood in high pressure reactor under saturated steam at 120,150 and $180^{\circ} \mathrm{C}$. Euro I Wood Wood Prod 72:33-41

\section{Publisher's Note}

Springer Nature remains neutral with regard to jurisdictional claims in published maps and institutional affiliations.

\section{Submit your manuscript to a SpringerOpen ${ }^{\circ}$ journal and benefit from:}

- Convenient online submission

- Rigorous peer review

- Open access: articles freely available online

- High visibility within the field

Retaining the copyright to your article

Submit your next manuscript at springeropen.com 